www.jmscr.igmpublication.org

Index Copernicus Value: 79.54

ISSN (e)-2347-176x ISSN (p) 2455-0450

crossref DOI: https://dx.doi.org/10.18535/jmscr/v7i5.25

\title{
Evaluation of RCH Services in Tertiary Care Hospital in Relation to Perinatal Outcome
}

\section{Dr Archana Paliwal ${ }^{1}$, Dr Rohit Dhandoria ${ }^{2}$, Dr Anjali Jain ${ }^{3}$, Rajaat Vohra ${ }^{4}$, Dr B. N. Sharma ${ }^{5}$}

${ }^{1}$ Associate Professor, Department of Community Medicine, Mahtma Gandhi Medical Collage \& University ${ }^{2} 3^{\text {rd }}$ year resident, Community Medicine, Mahtma Gandhi Medical Collage \& University

${ }^{4,5}$ Professor, Department of Community Medicine, Mahtma Gandhi Medical Collage \& University ${ }^{6}$ Professor \& Head, Department of Community Medicine, Mahtma Gandhi Medical Collage \& University *Corresponding Author

Dr Rohit Dhandoria

Email: drpcdhandoria@gmail.com

\section{Background}

The provision of RCH services are instrument in bringing down IMR and MMR, these two health indicators are the best key indicators reflecting health situation of any country.

Result: 855 mothers with their newborns were studied, a significant association was found between low birth weight and age of the mother at the time of delivery, parity and literacy level of mother, socioeconomic status of the family, birth spacing, ANC check up, consumption of iron/folic acid and any medical illness of mother like anemia.

Conclusion: The findings of present study reveals that unwanted perinatal outcome can be tackled by providing adequate antenatal care to pregnant women in time. To bring more and more women under Janani Shishu Suraksha Yojna (JSSY) and provide them adequate ANC, this will provide a long way to reduce adverse perinatal outcome.

This study designed to evaluate RCH services in relation to parinatal outcome.

\section{Introduction}

$\mathrm{RCH}$ programme was launched on Oct $15^{\text {th }} 1997$ in order to achieve health of mother and children, as collectively they constitute $65 \%$ of total population and are important vulnerable group in India due to high morbidity and mortality, hence identified as priority group. ${ }^{1}$

Each year over 27 millions babies are born in India accounting for 34 births per minutes. ANC is availed by less than $77 \%$ of pregnant women. ${ }^{2}$ There is over 1 lac women and one million neonatal babies dying in India every year due to pregnancy/delivery related causes. ${ }^{3}$ The alarming high neonatal and perinatal loss in India is attributed to several factors but leading cause is low birth weight (LBW) babies which account for over one third of all neonates. ${ }^{4}$ There are numerous factors contributing to LBW, both maternal and fetal .weight at birth is directly influenced by general level of health status of mother. Maternal environment is the most important determinant of birth weight, and factors 
that prevent normal circulation across the placenta cause poor nutrient and oxygen supply to the fetus, restricting growth. The maternal risk factors are biologically and socially interrelated, most of which are modifiable. A multifactorial inter relationship exists between the environment in which pregnant mother live and the growth of fetus. ${ }^{5}$

The spectrum of RCH services has been enlarged and emphasis has shifted from number of cases to quality and coverage services as also client satisfaction. The full range of maternal and child health services the concern with decentralized planning driven by client needs. ${ }^{6}$

\section{Materials and Methods}

A cross sectional study conducted at $\mathrm{MG}$ Hospital, Sitapura, A tertiary care hospital. All institutional deliveries comprise mothers and their new born babies with in the six months of study period, included in the study. A pre structured and pre tested questionnaire was used for collection of information.

The questionnaire had three components. First part includes information about new born- sex, birth weight, APGAR scoring and anthropometric measurement. Part second includes information regarding age, residence, religion, type of family, socio-economic status and residential environment of the family. Part third included information about obstetric history of mother, history of present pregnancy.
Before starting the study permission of the hospital ethical committee was taken and informed verbal consent was obtained from all the patients included in the study.

The data collected and entered in MS excel sheet and analysis was done by using appropriate statistical tools.

\section{Result}

Table 1 Demographic details about study participants

\begin{tabular}{|l|c|c|}
\hline Variable & No. $(\mathbf{n = 8 5 5})$ & \% \\
\hline Education & 225 & 26.26 \\
\hline Illiterate & 236 & 27.51 \\
\hline Primary & 394 & 46.23 \\
\hline secondary \& above & & \\
\hline Religion & 821 & 95.98 \\
\hline Hindu & 34 & 4.02 \\
\hline Muslim & & \\
\hline Socio-Economic Class & 51 & 5.96 \\
\hline I & 197 & 23.04 \\
\hline II & 284 & 33.22 \\
\hline III & 223 & 26.08 \\
\hline IV & 99 & 11.58 \\
\hline V & & \\
\hline
\end{tabular}

Table 2 Distribution of Neonates according to individual characteristic of Perinatal Outcome

\begin{tabular}{|c|c|c|}
\hline \multicolumn{2}{|l|}{ Characteristic } & \multicolumn{2}{|c|}{ Neonates } \\
\cline { 2 - 3 } & No. & $(\%)$ \\
\hline (1) Fetal outcome & & \\
a) Live & 796 & 93.09 \\
b) Perinatal Deaths & 59 & 6.90 \\
\hline (2) Sex & & \\
a) Male & 449 & 52.51 \\
b) Female & 406 & 47.49 \\
\hline (3) Birth Weight & & \\
a) <2.5kg & 237 & 27.72 \\
b) $\geq 2.5 \mathrm{~kg}$ & 618 & 72.28 \\
\hline
\end{tabular}

Table 3 Showing risk factors associated with low birth weight

\begin{tabular}{|c|c|c|c|c|c|c|c|c|}
\hline \multicolumn{2}{|l|}{ Risk Factor } & $\begin{array}{c}\mathbf{L B W} \\
(\mathbf{n}=237)\end{array}$ & $\%$ & $\begin{array}{c}\text { NBW } \\
(n=618)\end{array}$ & $\%$ & $x^{2}$ & df & p \\
\hline \multirow[b]{2}{*}{ Age of the mother } & $<25$ ears & 165 & 29.41 & 396 & 70.58 & 2.56 & 1 & 0.46 \\
\hline & $>25$ years & 72 & 24.48 & 222 & 75.51 & & & \\
\hline \multirow[b]{3}{*}{ Parity of mother } & primi & 124 & 32.8 & 254 & 67.2 & 9.49 & 1 & 0.023 \\
\hline & 2nd & 76 & 25.32 & 230 & 74.67 & & & \\
\hline & $\geq 3 \mathrm{rd}$ & 37 & 21.63 & 134 & 78.36 & & & \\
\hline \multirow[b]{2}{*}{ Birth spacing (in months) } & $\leq 35$ & 107 & 27.02 & 289 & 72.97 & 16.65 & 1 & 0.0001 \\
\hline & $>35$ & 6 & 7.4 & 75 & 92.59 & & & \\
\hline \multirow[b]{2}{*}{ ANC REC. } & yes & 106 & 18.24 & 475 & 81.75 & 75.45 & 1 & 0.001 \\
\hline & No & 131 & 47.81 & 143 & 52.18 & & & \\
\hline \multirow[b]{2}{*}{ Iron/folic acid received } & yes & 108 & 18.94 & 462 & 81.05 & 60.89 & 1 & 0.001 \\
\hline & No & 129 & 45.26 & 156 & 54.73 & & & \\
\hline \multirow[b]{2}{*}{ anemia in mothers } & yes & 165 & 37.75 & 272 & 62.24 & 42.15 & 1 & 0.001 \\
\hline & No & 72 & 12.22 & 346 & 82.77 & & & \\
\hline
\end{tabular}


The present study was conducted on 855 mothers and their newborns who delivered in Mahatma Gandhi Hospital, Sitapura, Jaipur within study period. Information was collected and analyzed accordingly. Majority (9598\%) of mothers were Hindu while only $(4.02 \%)$ were Muslim. More than one fourth $(26.26 \%)$ mothers were illiterate while $26.51 \%$ mothers were educated up to primary level and rests (46.23\%) were educated up to secondary and above. Most of the families belongs to middle and lower socio-economic status $(>60 \%)$.

Alarming high neonatal and perinatal loss in India is attributed to several factors, but the leading cause is low birth weight babies. Out of 855 babies delivered in the study duration 796 were live born while 59 were still born or parinatal death. Out of total 855 babies delivered 237 $(27.72 \%)$ were low birth weight, weighted $<2.5 \mathrm{~kg}$ and rest $618(72.24 \%)$ were of normal birth weight $(>2.5 \mathrm{~kg}) .52 .51 \%$ of all neonates were male and $47.49 \%$ were female, in our study the sex ratio was $904 / 1000$.

Mean age of mothers delivered within study period was 24.75 years. $66 \%$ mothers were age group <25 years. In our study $44.21 \%$ of mothers were primi para, $35.78 \%$ were second para. only $16.98 \%$ multipara mothers had birth space of more than 36 months while more than $80 \%$ had birth spacing $<36$ months.

Out of 855 mothers $67.96 \%$ were received antenatal care while $32.04 \%$ did not received ANC regularly or not at all. $66.71 \%$ females took iron and folic acid during their pregnancy period and $32.29 \%$ did not taken iron and folic acid sufficiently or not at all. $51.13 \%$ mothers were anemic (WHO criteria anemia in pregnancy $\mathrm{Hb}$ $<11$ gms).

In present study low birth weight is slightly higher in female babies $51.58 \%$ than male babies $48.42 \%$. There was high incidence of low birth weight babies in mothers of younger age group. Literacy status of mother had a positive impact on birth weight of new born as the literacy level of mother increases, proportion of LBW decreases and difference is statistically highly significant. Socio-economic status again had a significant impact on birth weight as proportion of low birth babies decreases as the socio-economic status improved.

Proportion of low birth weight babies is higher in primi and decreases as the parity is increases and the difference is statistically significant. Mother not received proper ANC checkup and regular iron $\&$ folic acid were also having more incidence of low birth weight babies in comparison with the mothers who received proper ANC checkup and iron folic acid during their pregnancy period association was found to be significant statistically.

Birth spacing also had significant impact on occurrence of incidence of low birth weight babies, spacing between two deliveries increases, proportion of LBW decreases. Proportion of low birth weight was higher who's mother were anemic and this difference statistically highly significant.

\section{Discussion}

Present study includes 855 mothers with their neonates who delivered in Mahatma Gandhi Hospital, Sitapura, Jaipur with the aim \& objective to evaluate RCH services in tertiary care hospital in relation to parinatal outcome. In the present study mean age of mother at the time of admission was 24.75 years. Similar had been shown by Uttekar BP at all (2007) ${ }^{7}$. during the study period among all 855 mothers, 93.09\% delivered live born while 6.90 had parinatal deaths. $52.51 \%$ of all neonates were male, $47.49 \%$ were female, $27.72 \%$ new born weighted $<2.5 \mathrm{~kg}$ in first hour of birth while $72.28 \%$ new born weighted $\geq 2.5 \mathrm{~kg}$. WHO $(1995)^{8}$, Joshi HS at all $(2005)^{9}$, Ravish KS (2006) ${ }^{10}$ observed similar findings in their study.

In our study proportion of low birth weight was slightly higher in the age group $<20$ years but the difference is not statistically significant. Similarly Abner $(1982)^{11}$ et al and Fernando \& Paul 
$(1987)^{12}$ found no significant association between LBW and maternal age.

In our study $26.26 \%$ mother were illiterate, $27.51 \%$ mothers were educated up to primary, $18.34 \%$ up to middle, $15.45 \%$ educated up to secondary level and $<13 \%$ were educated up to higher secondary and above. Uttekar BP et al (2007) also observed in their study in Rajasthan that majority of JSY beneficiaries were illetrate $(68 \%)^{7}$. The present study shows significant association between literacy level of mother and birth weight of their neonate. As the literacy level of mother increased incidence of low birth weight babies decreased and the difference is statistically highly significant. Similar findings are reported by Barker DJP (1998) ${ }^{13}$, Joshi SM, Pai NP (2000) ${ }^{14}$.

The present study showed a high incidence of LBW birth in primi mothers. 124 (52.49\%) LBW were born to primi mothers. There is a significant association between parity and low birth weight. Our findings are in accordance with many other workers who also showed this significant association namely Deshmukh JS et al $(1998)^{15}$.

Our study suggests that as birth spacing between two deliveries increases proportion of low birth weight babies decreases and association was statistically significant. Our findings are in accordance with Mavlankar DV, Gray RH and Trivedi CR (1992) ${ }^{16}$.

$67.96 \%$ mothers in our study had received adequate ante natal care while $32.04 \%$ mothers did not receive/inadequate ante natal care. Proportion of low birth weight babies were greater in the mothers who received inadequate ante natal care and association between availing proper ANC checkup and birth weight was found to be statistically highly significant. Joshi HS et al (2005) reported in their study that utilization of ANC (>3 Ante Natal Visit) in 58.20\% mothers. There was significant association between birth weight and utilization of ante natal care by mothers. ${ }^{9}$

In our present study $66.71 \%$ mothers had taken iron and folic acid during their pregnancy. In present study 407 (51.13\%) mothers had anemia.
Anemia in mothers is indicative of poor socioeconomic status, lack of ante natal care and less spacing, all these factors affect fetal growth and outcome. Most of studies found lower prevalence of anemia like Anand K and Garg BS (2006) reported that $35 \%$ of mothers had anemia. ${ }^{17}$ Out of 407 anemic mothers, number of low birth babies were 165 (37.84\%) which is quite high as compared with non anemic mothers (17.22\%). The difference was statistically highly significant. Our finding was also in accordance with Joshi HS et al $(2005)^{9}$.

\section{Conclusion}

Of 855 mothers studied, a significant association was found between low birth weight and age of mother at the time of admission, parity, literacy level of mothers, birth spacing, ANC check-up, consumption of iron/folic acid. Bases on the findings of this study following suggestions are made:-The proportion of low birth weight found to be high $27.76 \%$, it can be tackled by providing adequate antenatal care to pregnant women in time. To bring more and more women under Janani Shishu Suraksha Yojna (JSSY) and provide them adequate ANC, this will provide a long way to reduce birth of low birth weight babies.

\section{References}

1. Park K. Preventive and Social Medicine. 19thn edition. Jabalpur: Banarsidas Bhanot;2007

2. NFHS-III (National Family Health Survey-III), International Institute for Population Sciences, Mumbai, India, 2005-06, pg.191-222.

3. Kannan C (2007). A cross-sectional study of the profile and percentage of institutional deliveries among currently married women of 15-45 year age group in villages of Veerapandi Panchayat union of Salem district, Tamilnadu, Indian Journal of Community Medicine, October 2007; 32(4):305 
4. Guha's Neonatology principles and practice IIIrd edition, Jaypee brothers medical publishers (P) Ltd. 2005, P-27

5. Amin N, Abel R, Sampath Kumar V. Maternal risk factors associated with low birth weight. Ind $\mathrm{J}$ pediatrics. 1993;60(2):269-74

6. Indian council of medical research. Improving of quality and coverage of maternal and child health and family planning services at primary health centre level. An ICMR task force study (Summary report) NewDelhi:ICMR;1993.

7. Uttekar BP, Barge S, Khan W, Deshpande Y, Uttekar V, Sharma J et al. Assessment of ASHA and JSY in Rajasthan. 2007, Apr

8. WHO bridging the gape, The World Health Report, 1995, report of the director general

9. H.S. Joshi, Sh Subba, SB Dabral, S Dwivedi, D. Kumar and S Singh ; Risk Factors Associated with Low Birth Weight in Newborns; Indian Journal of Community Medicine Vol. 30, No. 4, October-December, 2005; 142-143

10. Ravish KS. Study of sociodemographic and maternal factors influencing low birth weight babies among institutional deliveries at Bijapur. Indian Journal of Community Medicine, 2006 Mar; URL: http://hdl.handle.net/123456789/735

11. Abner H, Levkeff, Milton Westphal M, Clinton Miller III Yvome Michal. Maternal risk factors in infants with very low birth weight. Obstet Gynecol 60:612, 91982)

12. Fernando Arias, Paul Tomich. Etiology and outcome of low birth weight and preterm infants. Obstet gynecol 60: 277, 1982

13. Barker DJP. Mothers, babies and health in later life. Edinburgh: Churchill Livingstone; 1998.
14. Joshi SM and Pai NP. Effect of maternal bio-social determinants on the birth weight in a slum area in Mumbai. Ind J. of Com Med. 2000 Jul-Sep;25(3):121-124

15. J.S. Deshmukh, D. D. Motghare, S. P. Zodpay and S. K. Wadhva Low Birth Weight and Associated Maternal Factors in urban area, Indian journal of Pediatrics Jan-1998 vol-35; 33-35

16. Mavalankar DV, Gray RH, Trivedi CR. Risk Factors for Preterm \& Term Low Birth Weight in Ahmadabad, India. International Journal of Epidemiology, Apr. 1992; 21:263-272

17. Kiran A, Garg B S. A study of factors affecting LBW. Indian Journal of community Medicine 2006. 